\title{
Diabetes and Weight Loss: a Pilot Study
}

\author{
Yen Ang, Teik Kee Ng, Chai Nyuk Chong, Keat Hui Ch’ng
}

\section{Introduction}

Most people with type 2 diabetes are found to be also obese. Research provides strong evidence linking obesity to diabetes, and that some weight loss can prevent the development of the disease or reduce its comorbidities $(1 ; 2)$. Diet and physical activities, often supported by pharmacotherapy remains the mainstay treatment for diabetes.

Malaysia has one of the highest diabetes prevalence in the world, and the highest obesity rate in South East Asia. Notably, the country has experienced a triple increase in DM2 (from 6\% to 20\%) and obesity (from 15\% to $40 \%$ ) incidences in the past 2 decades. Such dual epidemic is observed in many countries (5) and it is arguably not coincidental. As effective as it is in controlling hyperglycemia, medication does not treat the root of the problem-i.e, those risk factors that contribute to the development of disease or its complications, such as dietary habit, physical inactivity and obesity $(3 ; 4)$. There is a need to incorporate the management of those lifestyle risk factors into a comprehensive care plan for diabetes.

\section{Purpose/Method}

The primary objective of this study was to examine the feasibility of a program on weight loss through lifestyle modification on patients with diabetes.

Patients with diabetes or elevated blood sugar were referred to the lifestyle clinic at the hospital where they would be enrolled in a 10-week (70 days) weight loss program. The non-drug therapy consists of providing calorie-controlled healthy meals daily, 3 times a week exercise classes and once a week group classes focusing on motivation and behavioral change.

\section{About the AUTHORS \\ Adventist Lifestyle Centre, Penang Adventist Hospital, Malaysia}

\section{Results}

A total of 8 patients with diabetes history ranging from newly diagnosed to 30 years of duration were enrolled in the program. Everyone lost weight, between $4.8 \mathrm{~kg}$ to $12 \mathrm{~kg}$ ( $6 \%$ to $13.5 \%$ of total body weight), average weight loss of $8 \mathrm{~kg}(9.6 \%)$ in 10 weeks. For every $1 \%$ drop in body weight there is a corresponding $2 \%$ drop on fasting blood glucose. All 8 participants reduced their waist circumference by average of $7.4 \mathrm{~cm}(8 \%)$ and body fat by average $3.8 \%$.

The fasting blood glucose was lowered in every participant, with an average reduction of $18.6 \%$ or $1.5 \mathrm{mmol} / \mathrm{L}$. notably, the reduction is comparable to the effect achieved by some of the most commonly used glucose lowering medications (e.g., sulfonylureas or metformin). All participants improved their cardiovascular (CV) risk factors: reduction in blood pressure, triglycerides and waist circumference. One patient with 15 years of diabetes successfully weaned off insulin injection. Another one got off her diabetes medication completely.

\section{Discussion}

The causal relationship between excessive body fat and diabetes has been acknowledged over the past decades in the literature $(6 ; 7)$. Nonetheless, most diabetic care focuses on drug therapy, and very few incorporate health promotion focusing on weight loss. Though our number of cases is small, the finding in this pilot study suggest that weight loss through diet and exercise is effective in managing diabetes and many of its CV risk factors. The pilot study also suggests, that a loss of Body fat appears to increase insulin sensitivity of the diabetes patients.

\section{Conclusion}

Most non-pharmacological aspect of diabetic intervention involves diet, exercise and behavioral therapy. Our intervention provides all the above, plus a provision of daily caloric restricted meals to the diabetic patients with the aim of inducing weight loss. We do not just teach and motivate people to lose weight, we show them how by providing them the food. The intensive lifestyle therapy resulted in a significant amount of weight loss among the participants, who at the same time experienced improvement in many other health parameters, with some completely got off their medication.

Overall, this pilot study shows that the weight loss program is feasible for our Malaysian patient group. 


\section{Pilot Study}

Table 1 Change in weigth and cardiovaskolar risk factors for all participants

\begin{tabular}{|c|c|c|c|c|c|c|c|c|c|c|c|c|c|c|c|c|}
\hline \multirow[b]{3}{*}{ Participant } & \multirow{2}{*}{\multicolumn{2}{|c|}{ mographic Data }} & \multirow{2}{*}{\multicolumn{3}{|c|}{ Weight }} & & & & \multicolumn{8}{|c|}{ Cardiovaskolar (CV) Risk Factors } \\
\hline & & & & & & \multicolumn{3}{|c|}{$\begin{array}{l}\text { Body Mass Index } \\
\text { (BMI) }\end{array}$} & \multicolumn{3}{|c|}{ Waist Circumference } & \multicolumn{2}{|c|}{ Blood Pressure } & \multicolumn{3}{|c|}{ Triglycerides } \\
\hline & & & Before & After & Difference & Before & After & Diff & Before & After & Diff & Before & After & Before & After & \\
\hline$(n=8)$ & Age & Gender & $\mathrm{kg}$ & $\mathrm{kg}$ & $\%$ & $\mathrm{kgm}^{-2}$ & $\mathrm{kgm}^{-2}$ & $\%$ & $\mathrm{~cm}$ & $\mathrm{~cm}$ & $\%$ & $\mathrm{mmHg}$ & $\mathrm{mmHg}$ & $\mathrm{mmol} / \mathrm{L}$ & $\mathrm{mmol} / \mathrm{L}$ & $\%$ \\
\hline 1 & 47 & Male & 80.0 & 75.2 & -6 & 30.7 & 28.7 & -6.5 & 99 & 93 & -6.1 & $130 / 80$ & $124 / 71$ & 2.0 & 1.7 & -15.0 \\
\hline 3 & 51 & Female & 65.6 & 56.7 & -13.5 & 32.2 & 27.8 & -13.7 & 96 & 87 & -9.4 & $120 / 70$ & $105 / 70$ & 0.8 & 0.7 & -12.5 \\
\hline 4 & 53 & Female & 77.3 & 69.9 & -9.6 & 29.1 & 25.3 & -13.1 & 89 & 79 & -11 & $130 / 80$ & $120 / 80$ & 0.9 & 1.7 & +88.9 \\
\hline 5 & 58 & Female & 74.0 & 64.5 & -12.8 & 30.0 & 26.2 & -12.7 & 84 & 75 & -11 & $140 / 90$ & $120 / 90$ & 2.7 & 1.4 & -48.1 \\
\hline 6 & 60 & Female & 111.0 & 103.1 & -7.1 & 45.0 & 44.6 & -0.9 & 125 & 118 & -7.9 & $130 / 90$ & $140 / 80$ & 1.2 & 1.9 & +58.3 \\
\hline 7 & 61 & Female & 93.0 & 85.3 & -8.3 & 32.6 & 29.4 & -9.8 & 90 & 86 & -4.4 & $120 / 80$ & $120 / 80$ & 1.8 & 1.2 & -33.3 \\
\hline Mean & 56 & & 85.9 & 77.8 & -9.6 & 33.2 & 30.3 & -9.4 & 98.0 & 90.6 & -8.0 & $128 / 80$ & $123 / 77$ & 1.6 & 1.4 & 0 \\
\hline
\end{tabular}

Table 2 Fasting blood glucose changes for all participants

\begin{tabular}{cccccc} 
Participant & Before & After & \multicolumn{2}{c}{ Difference } & Years of DM \\
$(\mathrm{n}=8)$ & $\mathrm{mmol} / \mathrm{L}$ & $\mathrm{mmol} / \mathrm{L}$ & $\mathrm{mmol} / \mathrm{L}$ & $\%$ & \\
1 & 8.9 & 6.3 & -2.6 & -29.0 & 6 \\
2 & 5.7 & 5.0 & -0.7 & -12.0 & $\mathrm{~N} / \mathrm{A}^{*}$ \\
3 & 9.0 & 4.3 & -4.7 & -52.0 & $15^{* *}$ \\
4 & 10.2 & 9.6 & -0.6 & -5.9 & 18 \\
5 & 5.9 & 4.7 & -1.2 & -20.0 & $<1^{*}$ \\
6 & 6.7 & 6.2 & -0.5 & -7.5 & 10 \\
7 & 5.6 & 5.2 & -0.4 & -7.1 & $3 * * *$ \\
8 & 7.8 & 6.7 & -1.1 & -14.0 & 30 \\
\hline Mean & 7.5 & 6.0 & 1.5 & 18.6 &
\end{tabular}

N/A: Not Available

* Patients did not take any Oral Hypoglycemic Agent (OHA) prior to intervention

** Patient did not need insulin injection after intervention

*** Patient did not need OHA after intervention

\section{References}

(1) Leong KS, Wilding JP. Obesity and diabetes. Baillieres Best Pract Res Clin Endocrinol Metab. 1999; 13:221-37.

(2) Felber JP, Golay A. Pathways from obesity to diabetes. International journal of obesity and related metabolic disorders: journal of the International Association for the Study of Obesity. 2002; 26 Suppl 2:39-45.

(3) Ley SH, Hamdy O, Mohan V, Hu FB. Prevention and management of type 2 diabetes: dietary components and nutritional strategies. Lancet 2014; 383:19992007.

(4) Orozco LJ, Buchleitner AM, Gimenez-Perez G. Exercise or exercise and diet for preventing type 2 diabetes mellitus. The Cochrane database of systematic reviews. 2008; 3:CD003054.

(5) Hossain P, Kawar B, El Nahas M. Obesity and diabetes in the developing world - a growing challenge. The New England journal of medicine 2007; 356:213-5.

(6) Kenkre J, Tan T,Bloom S. Treating the obese diabetic. Expert review of clinical pharmacology. 2013; 6:171-83.

(7) Abdullah A, Peeters A, de Courten M, Stoelwinder J. The magnitude of association between overweight and obesity and the risk of diabetes: a meta-analysis of prospective cohort studies. Diabetes Res Clin Pract. 2010; 89:309-19. 